\title{
Frequency of $H$. pylori Antibodies among Patients with Gastrointestinal Symptoms Attending Khartoum Teaching Hospital- Sudan
}

\author{
Wafa Ibrahim Elhag ${ }^{1 *}$ and Leena Eltayeb Omer $\mathrm{Ali}^{2}$ \\ ${ }^{1}$ Microbiology Department, Faculty of Medical Laboratory Sciences, Al-Neelain University, Sudan \\ ${ }^{2}$ Faculty of Medical Laboratory Sciences, University of Science and Technology, Sudan
}

Received: December 09, 2013; Accepted: February 03, 2014; Published: February 06, 2014

*Corresponding author: Wafa Ibrahim Elhag Abd Elrahman, Microbiology Department, Faculty of Medical Laboratory Sciences, Al-Neelain University, 52nd St, Khartoum, Sudan, Tel: 012-233-3077; E-mail: wafaelhag75@yahoo.com

\begin{abstract}
A total of 90 patients with gastrointestinal symptoms, and who attended Khartoum Teaching Hospital during the period from April to October 2012, were enrolled in this study. Out of them 35 (38.9\%) were males and 55 (61.1\%) were females, their age ranges from 15-60 years with mean (33.2). The aim of this study was to detect frequency of Helicobacter pylori IgM, IgG antibodies, and to determine the relationship between the presence of antibodies and certain factors such as (sex, age and genetic susceptibility).

90 serum specimens were collected from patients, and analyzed by ELISA technique. The results showed that 19 (21.1\%), 57 (63.3\%) were positive for IgM antibody and IgG respectively, while 15 $(16.7 \%)$ were positive for both. Females were more affected than males, high frequency of positive results was observed among 15-30 age groups. Statistical analysis showed that there was insignificant correlation between age, gender, genetic susceptibility and presence of Helicobacter pylori antibodies $(\mathrm{P}>0.05)$.
\end{abstract}

Keywords: Helicobacter pylori; IgM; IgG; Antibodies; ELISA technique; Gastritis

\section{Introduction}

Helicobacter pylori (H. pylori) is the main causative agent of gastrointestinal diseases including chronic gastritis, peptic ulcer associated disorders, gastric and duodenal carcinomas leading to morbidity and mortality in humans $[1,2]$. Approximately two third of world population is infected with H. pylori, any age can get infection and women are affected just as often as men. $H$. pylori is more prevalent among the elderly and more frequent in males than females [3].

In February 1994, the National Institute of Health Consensus development conference concluded that $H$. pylori infection is major cause of peptic ulcer, and all patients with confirmed peptic ulcer associated with $H$. pylori infection should receive treatment with antimicrobial agent [4].

High prevalence of the pathogen was reported in developing countries as compared to low estimates in developed world. Several risk factors including; gender, age and existing lifestyle such as smoking habit, have a role in varying this prevalence [2]. To control such widespread infection, a recent quadruple treatment regimen combining proton pump inhibitor, clarithromycin, amoxicillin and nitroimidazole has been effectively used [5]. H. pylori is present on the gastric mucosa of less than $20 \%$ of persons under age 30 but increases in prevalence to $40-60 \%$ of persons age 60, including persons who are asymptomatic [5].

In developing countries, the prevalence of infection may be $80 \%$ or higher in adults. Person to person transmission of $H$. pylori is likely because intrafamilial clustering of infection occurs [6].

In Sudan, information about the prevalence of $H$. pylori infection is very patchy. and there is only one study which showed high prevalence (80\%) of $H$. pylori infection among patients with symptoms of gastritis, $56 \%$ with duodenal ulcer, while $60 \%$ with duodenitis and 16\% apparently look normal [7].

Colonization of human gastric mucosa by $H$. pylori stimulates specific cellular and humoral immune responses to bacterium [8]. Measurement of specific antibodies in serum has been used as non-invasive method by which $H$. pylori infection is detected [9]. Specific immunoglobulin M (IgM) antibodies can be detected shortly after has infection occurred, but IgA and IgG antibodies titers indicate chronic infection [9].

Early and prompt accurate diagnosis of $H$. pylori infection is crucially needed to identify any gastric diseases, limit further pathological complications and give rapid treatment to manage infected cases. The most frequent used diagnostic laboratory techniques are culture, stained smears, urease test, PCR assay, Western immunoblotting and histopathological examination of biopsy specimens $[10,11]$. However, these methods necessitate obtained gastric biopsy materials by an endoscopic invasive procedure [12]. Besides, cultural methods are time-consuming and show low sensitivity [11]. For this reason, serological assays such as Enzyme-linked immunoabsorbent assay (ELISA) have been utilized as non-invasive substitutes for diagnosis of infection [13]. 
As Helicobacter pylori causes a cocktail of several illnesses ranging from chronic gastritis, oesophagitis and ulcers to stomach and duodenal cancer. Proper and rapid laboratory assays are needed to diagnose infections in order to treat and manage the patient. Several techniques including culturing and molecular methods are present to identify the organism. The pathogen is difficult to grow and culturing procedure is laborious. Hence, serodiagnostic methods have been attempted to detect infection. This study aimed to detect frequency of Helicobacter pylori antibodies and its risk factors among patients with gastrointestinal symptoms attending Khartoum Teaching hospital.

\section{Materials and Methods}

This was descriptive- cross sectional study which had been conducted in Khartoum Teaching Hospital, during the period from April to October 2012. Ninety patients who had gastrointestinal symptoms (gasteritis, heartburn, peptic ulcer, nausea, vomiting, pain in upper abdomen and dark colored stool) and suspected to had H. pylori infection; were included, while patients who have no symptoms of $H$. pylori infection were excluded.

Data was collected by using direct interviewing questionnaire; the study was based on non probability- simple random technique.

Data was collected by using direct interviewing questionnaire; ethical clearance was obtained from Research Ethical Committee of the Faculty of Graduate Studies, Sudan University, and Ministry of Health- Khartoum State. Written consent was also obtained from the patients under supervision of physician.

Specimens ( 90 blood specimens) were collected under strict sterile condition, $5 \mathrm{ml}$ of whole venous blood was collected after disinfected of skin by $70 \%$ alcohol, and then the blood was poured in plain container and centrifuged at $2000 \mathrm{rpm}$ for 5 minutes to obtain the serum. Serum was stored at $-20^{\circ} \mathrm{C}$ until used.

Specimens were processed by means of ELISA (third generation, DRG instruments GmbH, Germany) for detection of H. pylori antibodies (IgM/ IgG).

\section{Enzyme linked immuno sorbent assay for the detection of IgM antibodies to $\mathrm{H}$. pylori in human serum}

Helicobacter pylori IgM test Kit (DRG instruments $\mathrm{GmbH}$ -Germany) is intended for use in evaluating the serologic status to $H$. pylori infection in patients with gastrointestinal symptoms.

ELISA assay procedure performed according to Warren and Marshall, 1983 [14]: All reagents were allowed to reach room temperature $\left(18-25^{\circ} \mathrm{C}\right)$ before used. One volume of wash buffer was diluted $(20 \times)$ with 19 volumes of distilled water. Microtitre plate was used, the desired number of coated wells were secured in the holder, A1 well for blank, negative control duplicate in wells $(\mathrm{B} 1, \mathrm{C} 1)$, positive control duplicate in wells (D1, E1), calibrator in wells (F1, G1) samples or testes in other wells.

One over forty dilutions with test samples, negative control, positive control and calibrator were prepared by added $5 \mu$ l of the sample to $200 \mu \mathrm{l}$ of sample diluents and mixed well.
One hundred micro liters of diluted sera, calibrator and controls was dispensed into the appropriate wells. $100 \mu \mathrm{l}$ of sample diluents was dispensed in $1 \mathrm{~A}$ well position, for the reagent blank. The holder was taped to remove air bubbles from the liquid and mixed well for 10 second.

The plate was incubated at room temperature for 30 minutes. At the end of the incubation period, the liquid from all wells was removed.

The microtiter wells were rinsed and flicked 4 times with diluted wash buffer $(1 \times)$ and then one time with distilled water, and then 100 micro liters of enzyme conjugate (Contain goat anti-human IgM conjugated to horseradish peroxidase with preservatives) was dispensed to each well and mixed gently for 10 seconds.

The plate was incubated at room temperature for 30 minutes. Then enzyme conjugate was removed from all wells, as in first washing.

One hundred micro liters of TMB (Contain 3,3',5,5 tetramethylbenzidine (TMB) stabilized in buffer solution) reagent was added to each well and mixed gently for 10 seconds and the plate was incubated at room temperature for 20 minutes. Then 100 micro liters of stop solution was added to each well including the 2 blanks. The plate was mixed gently for 30 seconds. It is important to make sure that all the blue color changes to yellow color completely. The optical density was read at $450 \mathrm{~nm}$ within 15 minutes with a microtiter plate reader.

Calculation of results: Calculation of (cut-off) of the mean of duplicate calibrator values $\left(\mathrm{x}_{\mathrm{c}}\right)$ and of the mean of duplicate positive control, negative control and patient samples were carried out. Calculation of the H. pylori IgM EIA index of each determination by dividing the mean values of each sample by calibrator mean value $\mathrm{x}_{c^{*}}$

\section{Interpretation of results:}

H. pylori IgM EIA index less than 0.90 was considered seronegative for IgM antibody to $H$. pylori.

H. pylori IgM EIA index between 0.91-0.99 was considered equivocal.

H. pylori IgM EIA index of 1.00 or greater was considered seropositive.

Helicobacter pylori IgG ELISA (DRG instrument $\mathrm{GmbH}$, Germany)

ELISA assay procedure performed according to Stolte, 1993 [15]: All reagents and required number of strips were allowed to reach room temperature before used. Wash solution was prepared: One volume of wash buffer was diluted $(20 \times)$ with 19 volumes of distilled water. This diluted wash solution has a $\mathrm{PH}$ value of $7.2 \pm 0.2$. Prior to assaying each patient specimen was diluted 1 over 100 with sample diluent. Standards and controls are ready for use and must not be diluted. The required number of microtiter strips or wells was selected and inserted them into the holder. 1 well (A1) for blank, 3 wells (from B1 to D1) for standard 
1, 2, 3. 2 wells (E1, F1) for negative control duplicate, 2wells (G1, H1) for positive control duplicate and samples duplicate in other wells.

One hundred micro liters of negative control, standard1, standard2, standard3, positive control and diluted samples were dispensed into appropriate wells. Well A1was left for substrate blank. The wells were covered with foil supplied in kit. The plate was incubated 60 minutes at $37^{\circ} \mathrm{C}$. After that the content of the wells were shock briskly and the wells was rinsed 5 times with diluted wash solution $(300 \mu \mathrm{l}$ per well), the wells were stroke sharply on absorbent paper to remove residual droplets.

One hundred micro liters of enzyme conjugate (horseradish peroxidase conjugated anti-human IgG antibodies) was dispensed into each well, except A1. Wells was covered with foil, and the plate was incubated 30 minutes at room temperature $\left(20^{\circ} \mathrm{C}\right.$ to $\left.25^{\circ} \mathrm{C}\right)$ away from direct sun light. Enzyme conjugate was removed from all wells, as mentioned before.

One hundred micro liters of substrate solution was added into all wells and the wells were covered with foil then incubated in the dark 15 minutes at room temperature $\left(20^{\circ} \mathrm{C}\right.$ to $\left.25^{\circ} \mathrm{C}\right)$. One hundred micro liters of stop solution was added to each well to stop the enzymatic reaction, any blue color developed during the incubation was hanged to yellow color. High positive patient samples can cause dark precipitates of the chromogen. The optical density at $450 / 620 \mathrm{~nm}$ was read with a microtiter plate reader within 30 minutes after adding the stop solution.

Calculation of qualitative results: Absorbance value of standard 1 (Cutt- off) $=$ CO $=15$.

Interpretation of qualitative results: Sample (mean) absorbance values more than $20 \%$ above CO (mean optical density (OD) of Sample > $1.2 \times$ CO) considered as positive result.

Sample (mean) absorbance values from CO to $20 \%$ above CO considered as grey zone. Should be repeated the test $2-4$ weeks later- with new patient samples ( $\mathrm{CO} \leq$ mean $\mathrm{OD}$ patient sample $\leq 1.2 \times \mathrm{CO}$ ).

Results in the second test again in the grey zone $\rightarrow$ Negative

Sample with (mean) absorbance values below CO (Mean OD patient $<\mathrm{CO}$ ) considered as negative result.

Data was analyzed by using statistical package for social science (SPSS) version (11.5), (Chi- square test).

\section{Results}

A total of 90 patients with gastrointestinal symptoms were enrolled in this study, in order to detect frequency of $H$. pylori using two immunoglobulins IgM and IgG, 35 (38.9\%) of study population were males and $55(61.1 \%)$ females, their age ranges from 15-60 years with mean (33.2).

Clinical information were also gathered, most of patients (64\%) suffering from heartburn, (63\%) abdominal pain. Table 1 demonstrated different clinical symptoms. Serum specimens were collected and processed by ELISA technique. 57 (63.3\%) of patients were positive for IgG antibody and 19 (21.1\%) were positive for IgM while $15(16.7 \%)$ of patients were positive for both and $29(32.2 \%)$ negative for both immunoglobulins Table 2.

Out of the total IgG positive patients $21(36.8 \%)$ were males and the remains were females $36(63.2 \%)$ and for IgM they were 4 (4.4\%) males and 15 (16.7\%) females Figure 1.

Among total patients $21(23.3 \%)$ had genetic susceptibility (according to gathered information), 6 (28.6\%) were positive for IgM, $11(52.3 \%)$ positive for IgG and the remain 4 (19.1\%) were negative for both Abs, also high positive results were observed among age group 15-30 as shown in Table 2 .

According to Chi- square analysis, there was insignificant correlation between gender, age, genetic susceptibility and presence of $H$. pylori antibodies $(\mathrm{P}>0.05)$ as shown in Table 3.

\section{Discussion}

H. pylori infection is a cofactor in the development of three important upper gastrointestinal diseases, duodenal or gastric ulcers, gastric cancer and gastric mucosa-associated lymphoid tissue (MALT) lymphoma [16]. In Sudan the prevalence of peptic ulcer disease is about $18-30 \%$ so it is very common disease [17]. Therefore the right diagnosis of Helicobacter pylori infections

Table 1: Distribution of gastrointestinal symptoms among study population.

\begin{tabular}{|l|l|}
\hline Symptomst & No (percent \%) \\
\hline Gastritis & $43(48 \%)$ \\
\hline Peptic ulcer & $32(36 \%)$ \\
\hline Heartburn & $58(64 \%)$ \\
\hline Pain in upper abdomen & $57(63 \%)$ \\
\hline Lack of appetite & $38(42 \%)$ \\
\hline Nausea/vomiting & $52(57 \%)$ \\
\hline Dark color stool & $17(19 \%)$ \\
\hline Feeling full after eating small amount of food & $36(40 \%)$ \\
\hline
\end{tabular}

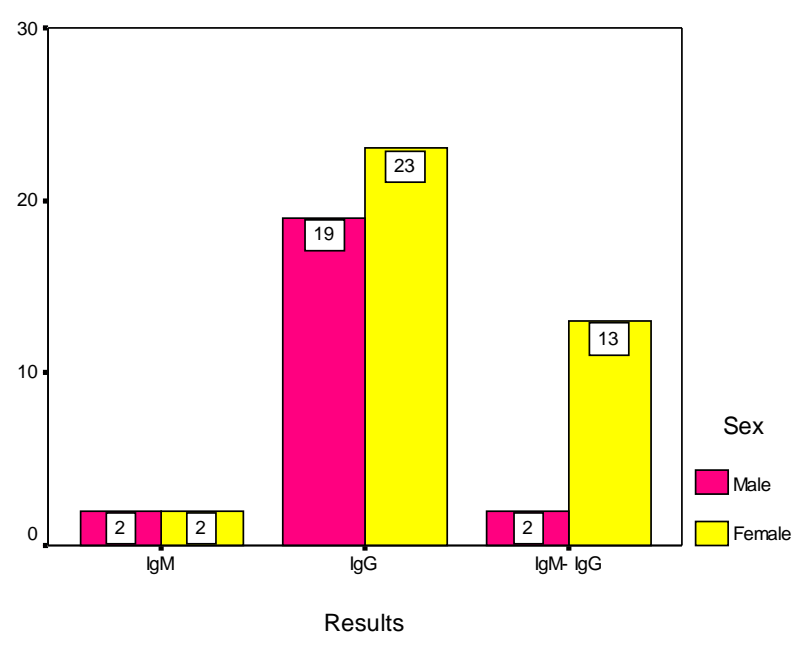

Figure 1: Frequency of seropositive H. pylori Abs according to sex. 
Table 2: Serofrequency of $H$. pylori antibodies among different age groups.

\begin{tabular}{|l|l|l|l|l|}
\hline \multirow{2}{*}{ Age groups } & \multicolumn{4}{|l|}{ Results } \\
\cline { 2 - 5 } & $\begin{array}{l}\text { IgM } \\
\text { seropositive }\end{array}$ & $\begin{array}{l}\text { IgG } \\
\text { seropositive }\end{array}$ & $\begin{array}{l}\text { IgM-IgG } \\
\text { seropositive }\end{array}$ & Negative \\
\hline $15-30$ & $12(13.3 \%)$ & $29(32.2 \%)$ & $9(10.0 \%)$ & $16(17.8 \%)$ \\
\hline $31-45$ & $5(5.6 \%)$ & $15(16.7 \%)$ & $5(5.6 \%)$ & $7(7.8 \%)$ \\
\hline $46-60$ & $2(2.2 \%)$ & $13(14.4 \%)$ & $1(1.1 \%)$ & $6(6.7 \%)$ \\
\hline Total & $19(21.1 \%)$ & $57(63.3 \%)$ & $15(16.7 \%)$ & $29(32.2 \%)$ \\
\hline
\end{tabular}

Table 3: Relation between H. pylori antibodies and certain factors (age, gender and genetic susceptibility) - Chi-square test.

\begin{tabular}{|l|l|l|}
\hline Immunoglobulin & Factors & P-value (0.05) \\
\hline IgM & Age & 0.38 \\
\hline IgG & Age & 0.81 \\
\hline IgM & Gender & 0.07 \\
\hline IgG & Gender & 0.60 \\
\hline IgM & Genetic susceptibility & 0.34 \\
\hline IgG & Genetic susceptibility & 0.23 \\
\hline
\end{tabular}

is one of the important issues that require special and specific tests, equipments and skilled personnel [18]. In epidemiological studies, serum tests could offer high sensitivity and specificity. Assaying of serum for anti-H. pylori IgG or IgM antibodies could be used to determine prevalence of acute and chronic infections $[19,20]$.

This study was designed to detect the frequency of $H$. pylori among patients with gastrointestinal symptoms through IgM, IgG antibodies detection.

In the present study, 90 patients were enrolled, the result showed that $57(63.3 \%)$ positive for IgG antibody, $19(21.1 \%)$ were positive for IgM antibody and 15 (16.7\%) for both. These results are slightly similar to which reported in Kenya by Jontathan and his colleagues (2003), who found $20 \%$ and $70.2 \%$ seropositive for IgM, IgG respectively [21], also it is similar to result reported in Saudi Arabia by Mubashir and Hani they found that $62.7 \%$ and $22 \%$ were seropositive for IgM, IgG respectively [22].

However our results were different from that of Garza and his co- workers (2006) in Spain, who found that IgM was (33.3\%) and IgG (24\%) [23]. This difference may be due to difference in nutritional behavior, socioeconomic status, water supply, educational level and environmental condition or others.

The present study results showed insignificant correlation between age and $H$. pylori antibodies, this was similar to study done in Iran by Alavi and others in 2010 [24], but it differ from Kabir, (2007) in Sweden who reported that the percentage of infected people increase with age [25]. Also Forman and Burley in 2006, stated that the prevalence of H. pylori infections increase, with age [26].

In this study the higher percentage of infection observed among age group 15-30 years, this high percent may be due to the vast majority of individuals acquire this infection during childhood [27], also the infection associated with low socioeconomic status, poor hygiene and overcrowding [28].

On the other hand our study observed that the females were more affected than males, but statistically there was insignificant correlation between $H$. pylori antibodies and gender ( $\mathrm{P}>0.05)$, Our result was similar to that of Mirghani and his co- workers in Sudanese patients, they found there is insignificant difference between males \& females for H. pylori antibodies [29], and was in agreement with that obtained in Egypt by Manal et al., (2007) [30], other studies by Huang et al., (2004) in Malaysia [31], Kikuchi and others (2005) in Iran [32], and Mukherjee et al., (2005) in Netherlands [33]. In contrast, Leandro et al., (2005) found that the prevalence was significantly higher in boys [34], also Versalovic and Fox, (2003) reported that H. pylori is more prevalent among the elderly and more frequent in males than females [35].

The present study showed insignificant correlation between genetic susceptibility and $H$. pylori IgM, IgG ( $\mathrm{P}>0.05$ ), which was dissimilar to study done in United States of America (Texas) by Malaty et al., (2001) who found it was significant [36].

\section{Conclusion}

This study concluded that the frequency of H. pylori IgG, IgM were 57 (63.3\%) and 19 (21\%) respectively, and 15 (16.7\%) for both. Female were more affected than males, high antibodies frequency observed among 15-30 years old. Statistical analysis showed insignificant correlation between gender, age, genetic susceptibility and presence of $\mathrm{H}$. pylori antibodies.

\section{References}

1. Black JG (2004) Microbiology Principles and exploration. ( $6^{\text {th }}$ edn), John Wiley \& Sons, USA.

2. Baik SJ, Yi SY, Park HS, Park BH (2012) Seroprevalence of Helicobacter pylori in female Vietnamese immigrants to Korea. World J Gastroenterol 18(6): 517-521.

3. Yamoka Y (2010) Mechanisms of disease: Helicobacter pylori virulence factors. Nat Rev Gastroenterol Hepatol 7(11): 629-641.

4. Yamada S, Matsuhisa T, Makonkawkeyoon L, Chaidatch S, Kato S, et al. (2006) Helicobacter pylori infection in combination with the serum pepsinogen I/II ratio and interleukin-1beta-511 polymorphisms are independent risk factors for gastric cancer in Thais. J Gastroenterol 41(12): 1169-1177.

5. Gisbert JP, Calvet X (2012) Update on non-bismuth quadruple therapy for eradication of Helicobacter pylori. Clin Exp Gastroenterol 5: 23-34.

6. Carroll KC, Brooks GF, Butel JS, Morse SA, Mietzner TA (2010) Medical Microbiology. (25 ${ }^{\text {th }}$ edn), 235-240.

7. Elbagir M, Ahmed K (2001) Duodenal ulcer in Sudan. Sudan Medical Journal 24:1-39.

8. Sharma TK, Young EL, Miller S, Cutler AF (1997) Evaluation of a rapid, new method for detecting serum IgG antibodies to Helicobacter pylori. Clin Chem 43(5): 832-836.

9. Crabtree JE, Mahony MJ, Taylor JD, Heatley RV, Littlewood JM, et al. (1991) Immune responses to Helicobacter pylori in children with recurrent abdominal pain. J Clin Pathol 44(9): 768-771. 
10. Rocha GA, Rocha AM, Silva LD, Santos A, Bocewicz AC, et al. (2003) Transmission of Helicobacter pylori infection in families of preschoolaged children from Minas Gerais, Brazil. Trop Med Int Health 8(11) 987-991.

11. Deankanob W, Chomvarin C, Hahnvajanawong C, Intapan PM Wongwajana S, et al. (2006) Enzyme linked immunosorbent assay for Serodiagnosis of Helicobacter pylori in dyspeptic patients and volunteer blood donors. Southeast Asian J Trop Med Public Health 37(5): 958-965.

12. Hanvivatvong O, Atinop P, Niramol T, Pinit K (2004) Evaluation of commercial Immunoassays for detection of antibody against Helicobacter pylori in Thai Dyspeptic Patients. Clin Diagn Lab Immunol 11(3): 618-620.

13. Goddard AF, Logan RP (2003) Diagnostic methods for Helicobacter pylori detection and eradication. Br J Clin Pharmacol 56(3): 273-283.

14. Warren JR, Marshall BJ (1983) Unidentified curved bacilli on gastric epithelium in active chronic gasteritis. The Lancet 321(8336): 12731275 .

15. Stolte M, Eidt S (1993) Healing gastric MALT lymphomas by eradicating H. pylori. The Lancet 342: 568.

16. Kenneth EL, McColl MD (2010) Helicobacter pylori Infection. N Engl J Med 362: 1597-1604.

17. Elmahadi AM, Patchett SE, Domizio P, Fedial SS (2003) Acid response to $\mathrm{H}$. pylori infection in an African population. J Clin Microbiol 39(4): 1323-1327.

18.Saad R, Chey WD (2005) A clinician's guide to the managing Helicobacter pylori infection. Cleve Clin J Med 72(2): 109-126.

19. Locatelli A, Catapani WR, Gomes CR Jr, Silva CB, Waisberg J (2004) Detection of anti- Helicobacter pylori antibodies in serum and duodenal fluid in peptic gastroduodenal disease. World J Gastroenterol 10(20): 2997-3000

20. Atalay C, Atalay G, Altinok M (2003) Serum Helicobacter pylori IgG and IgA levels in patients with gastric cancer. Neoplasma 50: 185-190.

21. Siekmann JH, Allen LH, Watnik MR, Nestel P, Neumann CG, et al (2003) Titers of antibody to common pathogens: relation to foodbased interventions in rural Kenyan schoolchildren. Am J ctin Nutr 77(1): 242-249.

22. Mubashir AK, Hani OG (2007) Helicobacter pylori infection in asymptomatic subjects in Makkah, Saudi Arabia. J Pak Med Assoc 57(3): 114-116.

23. Garza YM Lopez GA Martinez PD, Galindo GJA, Cuevas AMT, et al (2006) Prevalencia de seropositivdad a anticuerpos IgG e IgM contra
Helicobacter pylori en el personal médico residente del Hospital Universitario de Puebla. Rev Alergia Mex 53(2): 69-72.

24. Alavi SM, Adel SMH, Raja AR (2010) Seroprevalence study of Helicobacter pylori infection among visitors of cardiac patients in Razi Hospital in Ahvaz, Iran. Jundishapur J Microbiol 3(1): 28-31.

25. Kabir S (2007) The current status of Helicobacter vaccines. a review. Helicobacter 12(2): 89-102.

26. Forman D, Burley VJ (2006) Gastric cancer: global pattern of the disease and an overview of environmental risk factors. Best Pract Res Clin Gastroenterol 20(4): 633-649.

27. Chey WD Wong BC (2007) American College of gastroenterology guideline on the management of Helicobacter pylori Infection. Am J Gastroenterol 102(8): 1808-1825.

28. Cherian S, Forbes D, Sanfilippo F, Cook A, Burgner D (2008) Serodiagnosis of Helicobacter pylori evolution of rapid miniapurized immunochromatographic test. Med J 8: 438-415.

29. Mirghani YA, Salah AM, Fedial SS (2002) Detection biochemical and immunological characterization of H. pylori in Sudanese patients with gastro duodenal inflammation. M.Sc. Thesis 92-U. Khartoum.

30. Manal E Kandil, Azza El Hamshary, Nahed AR Emara (2007) Seroprevalence of Helicobacter pylori in juvenile rheumatoid arthritis and its relation to disease severity. Journal of Medical Sciences 7(5): 716-723.

31. Huang SS, Hassan AK, Choo KE, Ibrahim MI, Davis TM (2004)? Prevalence and predictors of Helicobacter pylori infection in children and adults from the Penan ethnic minority of Malaysian Borneo. Am J Trop Med Hyg 71(4): 444-450.

32. Kikuchi S, Dore MP (2005) Epidemiology of Helicobacter pylori infection. Gastroenterology \& Hepatology 10: 1-10.

33. Mukherjee P, Chacko B, Singh T, Pawar G, Kaur H (2005)Prevalence of Helicobacter pylori infection in children with recurrent abdominal pain. Trop Gastroenterol 26(2): 102-104.

34. Leandro Liberato SV, Hernandez Galindo M, Torroba Alvarez L, Sanchez Miramon F, Leandro Ciriza SE, et al. (2005) Helicobacter pylori infection in the child population in Spain: Prevalence, related factors and influence on growth. An Pediatr (Barc) 63(6): 489-494.

35. Versalovic J, Fox JG (2003) Manual of Clinical Microbiology. ( $8^{\text {th }}$ edn), Washington DC (1): 915-928.

36. Malaty M, Engstrand L, Pedersen NL, Graham DY (2001) Helicobacter pylori infection: genetic and environmental influences. A study of twins. Ann Intern Med 120(12): 982-986. 